\title{
Simulation of the Plug inside Open Steel Pipe Piles with Regards to Different Installation Methods
}

\author{
Johannes Labenski ${ }^{1}$, Christian Moormann ${ }^{2}$, Johannes Aschrafi ${ }^{3}$, Britta Bienen ${ }^{4}$ \\ ${ }^{1,2,3}$ Institute for Geotechnical Engineering, University of Stuttgart, Germany \\ ${ }^{4}$ Centre for Offshore Foundation Systems, University of Western Australia, Perth, Australia \\ E-mails: ${ }^{j}$ johannes.labenski@igs.uni-stuttgart.de (corresponding author); \\ 22christian.moormann@igs.uni-stuttgart.de; 3johannes.aschrafi@igs.uni-stuttgart.de; \\ ${ }^{4}$ britta.bienen@uwa.edu.au
}

\begin{abstract}
Open steel pipe piles are used for various applications in costal engineering and port structures and they are becoming increasingly more important for offshore structures. A plug formed during the installation of open steel pipe piles has an influence on the installation process of the steel pipe pile as well as on the final bearing behaviour and the pile resistance. Forming of the plug depends on different influences, e.g. the pile diameter, the soil conditions and the installation method. To obtain a better understanding of the formation of the plug and its consequences several experimental small-scale tests, experimental field tests and numerical simulations have been performed. But so far this phenomenon is not completely investigated yet. At the beginning of this paper a structured overview about the characterization of the plug as well as soil mechanical processes during the pile installation in non-cohesive soil are provided. Then, the results of a centrifuge study are shown. The focus of this paper is the numerical simulation of the installation process of impact and vibratory driven piles in non-cohesive soil to investigate the effect of plugging with regard to different installation methods. Centrifuge experimental results are utilized to validate the numerical model, which can provide detailed insights into the physical processes occurring in the soil but are difficult to measure in experiments. The numerical analyses hence illustrate zones of densification/loosening, which highlight the differences resulting from the installation methods.
\end{abstract}

Keywords: pipe piles, soil plug, Coupled Eulerian-Lagrangian, hypoplasticity, non-cohesive soil, numerical simulation.

Conference topic: Design experiences and theoretical solutions.

\section{Introduction}

The axial bearing behaviour of open steel pipe piles depends, among others, on the pile diameter, the embedment length of the pile, the interface friction angle between the pile and the soil, the relative density of the soil and the installation method. During the installation a so called plug can form inside the pile, which influences the axial bearing behaviour significantly.

The axial bearing behaviour, respectively resistance, is developed by the frictional resistance of the pile shaft $\left(\tau_{\mathrm{s}}\right.$ and $\tau_{\mathrm{is}}$ ) and the base resistance of the pile toe $\left(\mathrm{q}_{\mathrm{b}, \mathrm{an}}\right.$ and $\mathrm{q}_{\mathrm{b} \text {,plug }}$ ) (Fig. 1). The frictional resistance is mainly influenced by the shear resistance of the soil, the material and roughness of the pile and the radial stress acting on the pile shaft.

According to Lüking (2010) a plug is arching between the opposite jacked surfaces inside the open steel pipe pile. This arching is not acting on the whole height of the soil layer inside the steel pile but is confined to the pile toe. According to Lüking and Kempfert (2012) this arching exists only at the last two pile diameters. To reliably determine if there is a plug inside the steel pipe pile, the radial stress in the soil at the pile toe on the in- and outside of the shaft has to be measured. If the measured radial stress at the inside is higher compared to the outside, plugging effects can be assumed (Henke 2013). Another way to identify the plugging behaviour of an open pipe pile is the Incremental Filling Ratio (IFR) by Brucy et al. (1991) which is defined as follows:

$$
\mathrm{IFR}=\Delta \mathrm{h} / \Delta \mathrm{L},
$$

where $h$ - the height of the soil inside the open steel pipe pile, $\mathrm{L}$ - the embedded length of the pile inside the soil (Fig. 1) and $\Delta-$ incremental value, i.e. for every x meters of driving the corresponding values have to be determined and the respective IFR has to be calculated.

Three different situations come to rise: IFR equal zero, IFR equal one and IFR less than one. An IFR with the value zero means that the pile is closed, i.e. there is no soil inside the pile and $\Delta \mathrm{h}$ is always zero. In this case the radial stress around the pile tip is high. An IFR of one means that the soil inside the pile is not moving downwards, i.e. there is no plug and $\Delta \mathrm{h}$ equals $\Delta \mathrm{L}$. In this case the radial stress around the pile tip does not differ significantly from the initial stress state. An IFR with a value less than one means that there is partial plugging inside the open steel pipe pile. The radial stress at the pile toe is higher compared to an unplugged open steel pipe pile, but lower compared to a closed-ended steel pipe pile. 


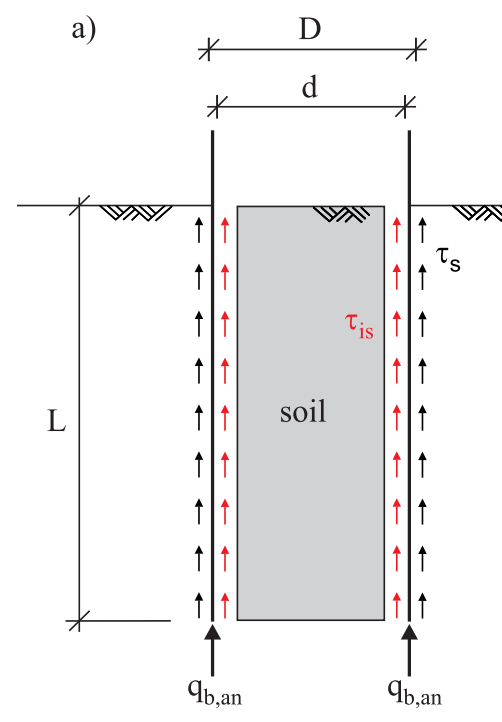

b)

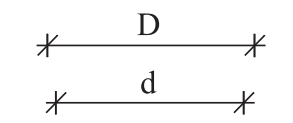

c)

)
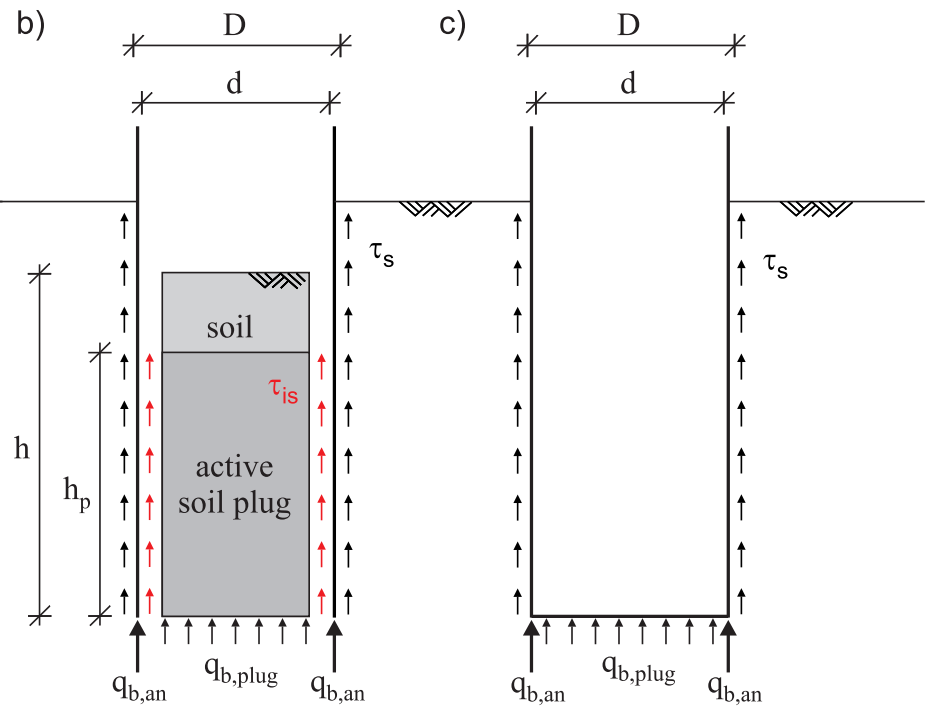

Fig. 1. Characterization of a soil plug: a) no plugging effect (IFR $=1)$, b) partially plugged $(0 \leq \operatorname{IFR} \leq 1)$, c) fully plugged $(\mathrm{IFR}=0)$.

\section{Soil mechanical process during the installation}

\section{Impact driving}

During the impact-driven installation of piles, the stress in the soil as well as the soil state parameters are horizontally influenced up to a distance of 7 to $12 \mathrm{D}$ and vertically influenced up to a depth of 3 to $5 \mathrm{D}$ underneath the pile toe (Hartung 1994).

In the area around the pile toe, the soil is compacted. Thus, the vertical and horizontal stresses increase. Around the pile shaft, the soil is contracting if the relative density of the soil is loose. If the relative density of the soil is dense, the soil around the pile shaft is dilating during installation. If the soil is dilating, the radial stress acting on the shaft is increasing. However, if the displacement of the sand grains is exceeding a certain limit, this effect is inverted and the radial stress is decreasing. This effect is visualized in Figures 2 and 3 .

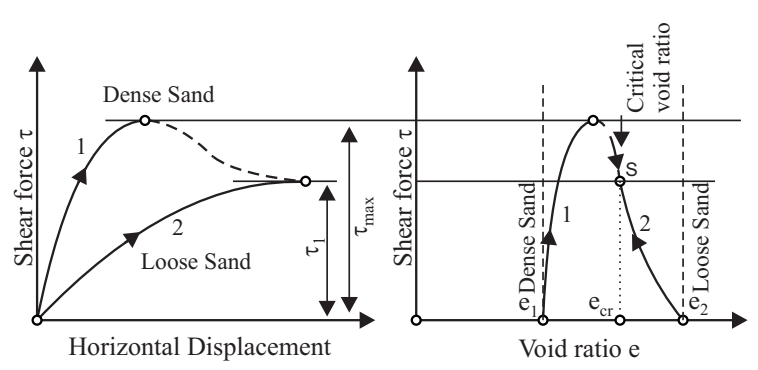

Fig. 2. Behaviour of the void ratio after exceeding the peak $\tau_{\max }$ according to Kezdi (1969) and Hartung (1994)

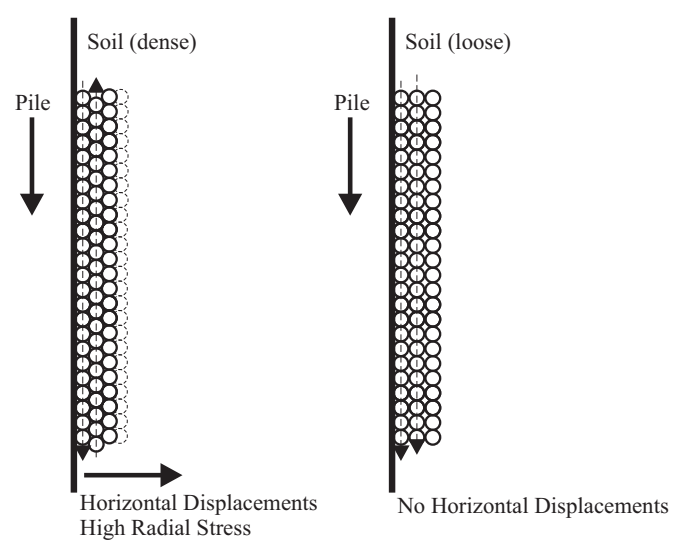

Fig. 3. Pile-soil interaction of dense and loose sand according to Hartung (1994)

\section{Vibratory driving}

During the vibratory-driven installation the pile is vertically excited by a dynamical force acting down- and upwards. This vertical excitation of the pile leads to an excitation of the soil grains which are moved not only vertically, but also horizontally or in all directions respectively (Hartung 1994). This way the soil around the pile shaft is transformed into a Newtonian fluid, which is not able to resist shear forces. Thus, the pile is able to sink to the desired embedment length just by its own weight and an optional surcharge.

In accordance with findings by Hartung (1994) for piles vibratory driven with a frequency of $40-50 \mathrm{~Hz}$, the soil around the pile shaft during installation can be divided into two different zones: a liquefaction zone and a compaction zone. Due to the dynamical excitation the soil grains in the liquefaction zone are moving with high velocities leading to a higher volume of the soil in this 
area. Also the horizontal stress is significantly lowered. In the compaction zone the horizontal stress in the soil shows high values. This phenomenon is illustrated in Figure 4. After pile driving, the relative density in the liquefaction zone is low while there is a high relative density in the compaction zone. In the area around the pile toe, the soil is behaving similarly. These effects lead to decreased shaft friction and end bearing of the pile in comparison to the impact-driven pile.

However, Hartung (1994) and Lammertz (2008) state that increased shaft friction and end bearing can occur in non-cohesive soils with a loose initial density by vibrating the pile during the installation close to the eigenfrequency of the soil.

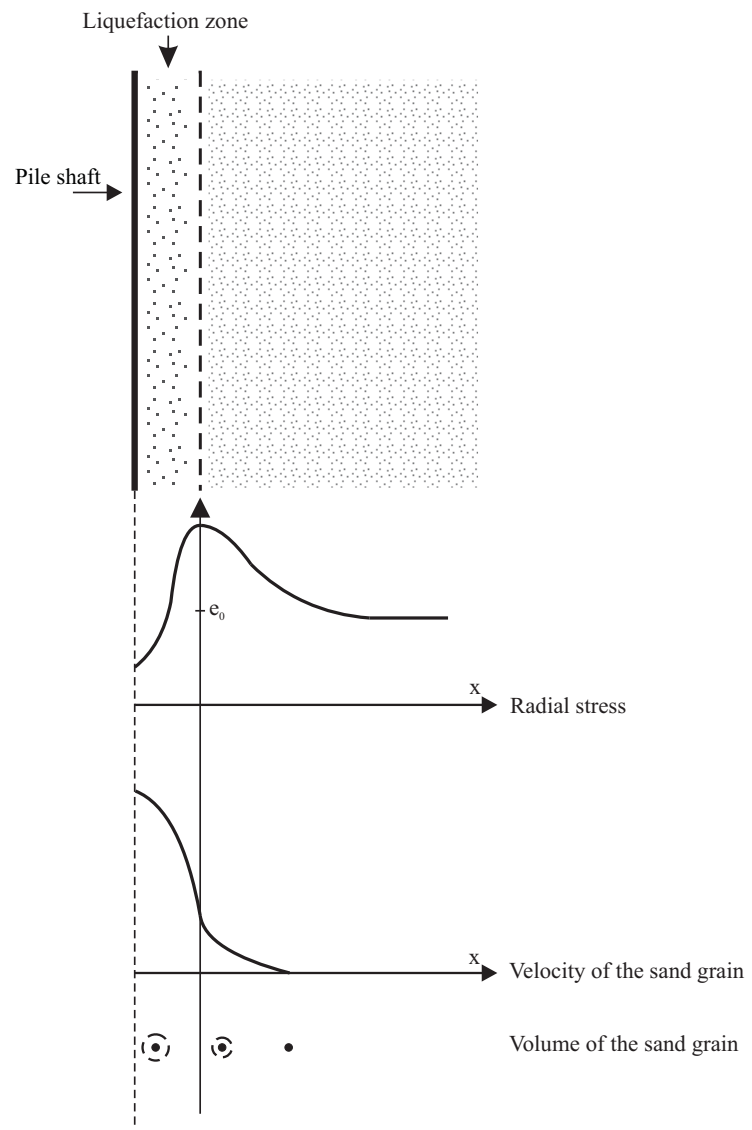

Fig. 4. Pile - soil interaction during vibratory driving according to Hartung (1994)

\section{Experimental investigations}

The influence of pile geometry, soil density and installation method on soil plug formation were addressed in a systematic experimental study by Henke and Bienen $(2013,2014)$. In order for the tests at model scale to reflect prototype behaviour, the experiments were carried out at enhanced gravity $(50 \mathrm{~g})$ in a geotechnical centrifuge (Fig. 5). This ensures similitude of the stress field in the soil between model and prototype and for representative failure mechanisms to form. The results can be related to field conditions via established scaling laws (Garnier et al. 2007).
The investigation of the effect on the installation method on plugging of open-ended piles in this study included:

1. Jacking,

2. Vibratory driving, and

3. Impact driving.

The quasi-static jacking was achieved through displacement-controlled installation of the pile at a constant rate. This was superposed with sinusoidal motion to obtain idealised vibratory driving. A miniature pile driving hammer (Fig. 5, de Nicola and Randolph 1994, but completely refurbished and upgraded to current standard) was used for pile driving with a prototype mass of $6.25 \mathrm{t}$, a falling height of $0.5 \mathrm{~m}$ and a driving frequency of $10 \mathrm{~Hz}$.

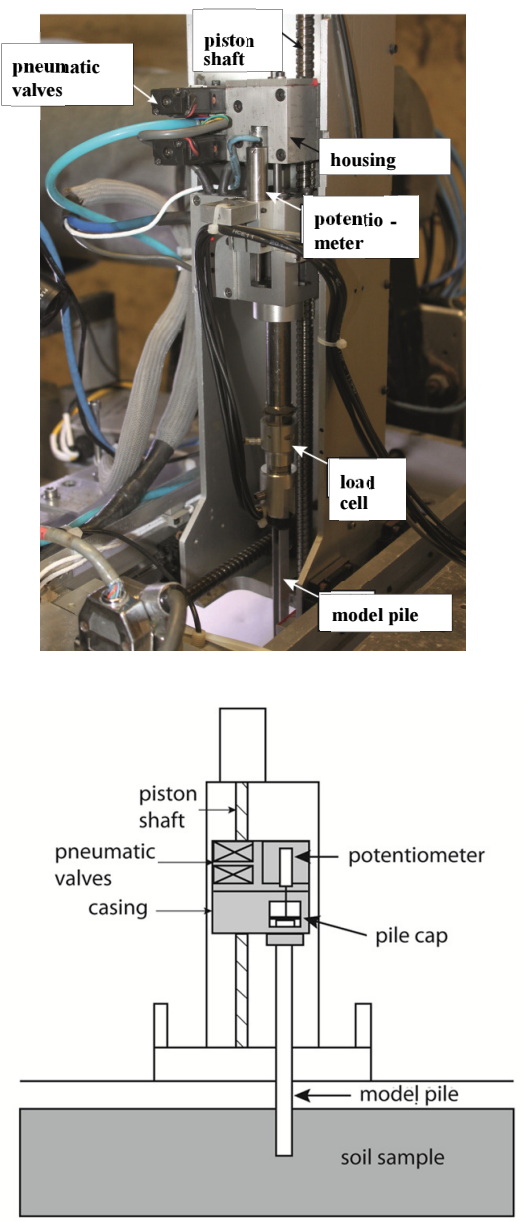

Fig. 5. Miniature pile driving hammer

The experiments on a $0.83 \mathrm{~m}$ diameter (prototype) tubular pile in uniform dry silica sand with $\mathrm{d}_{50}=0.19 \mathrm{~mm}$, prepared to a relative density $\mathrm{D}_{\mathrm{r}}=30 \%$, showed a clear dependency of soil plug formation on the installation method. Jacking was demonstrated to lead to a significant increase in internal skin friction. Hence, soil plug formation is likely when the pile is jacked. In vibratory driven piles, plugging is deemed unlikely as internal 
skin friction and base resistance are significantly reduced. Further, the internal soil column was shown to compact. The results were even clearer for impact driving, which is deemed to have a low tendency for soil plug formation.

These centrifuge experiments followed earlier work that focused on the plugging tendency of jacked or driven tubular piles in silica sand (de Nicola 1994; de Nicola, Randolph 1997) and uncemented as well as cemented calcareous sand (Bruno 1999). The results are further supported by results in Randolph (2003), indicating that plug formation is unlikely in impact driven piles due to inertia of the internal soil column.

\section{Discussion}

In the previous sections, the principle mechanical mechanisms in the soil during installation as well as the definition and characterization of plugging effects inside open steel pipe piles has been shown. It is apparent that plugging effects in open steel pipe piles can have a significant influence on the axial bearing behaviour. Therefore a realistic prediction of plugging effects during the axial pile design is necessary.

It was shown, too, that the effect of plugging strongly depends on - and can be characterized with- the radial stress acting on the pile shaft at the in - and outside of the pile. During the impact-driven installation the radial stress acting on the pile shaft is increasing, while the radial stress during vibratory-driving is decreasing in the direct vicinity of the pile.

To investigate the effect of plugging, several smallscale tests, field tests and numerical simulations have been carried out in the past. But so far this phenomenon is not completely investigated yet. The aim of this paper is to use a numerical model, which is validated against a physical model, to gain deeper insights into the effect of plugging. Especially the soil mechanical process during pile installation is of interest, as this cannot be fully captured by physical model tests. Afterwards the validated numerical model can be taken to further vary the boundary conditions and their influence on the effect of plugging. The so obtained results can serve to improve current design methods.

\section{Numerical simulation}

The numerical simulation of the steel pipe pile installation into soil is a large deformation problem. A standard Lagrangian finite element simulation would fail because of the high extent of mesh distortion. To overcome this problem, the Coupled Eulerian-Lagrangian (CEL) method is used. Qiu et al. (2009), Moormann and Aschrafi (2014) and Moormann et al. (2015), amongst others, already showed the potential of the CEL method for geotechnical applications undergoing large deformations. To simulate the behaviour of the soil a hypoplastic constitutive law is used here. The numerical simulation of the installation of an open steel pipe pile was carried out using the software Abaqus/Explicit (Dassault Systèmes 2014).

\section{Numerical method}

The CEL method harnesses the advantages of both the Lagrangian and Eulerian method. For geotechnical problems, a Lagrangian mesh is used to discretize structures; while an Eulerian mesh is used to discretize the subsoil. During the numerical analysis the Eulerian material is tracked as it flows through the mesh, hence avoiding mesh distortion, by computing its Eulerian Volume Fraction (EVF). Each Eulerian material is designated a percentage, which represents the portion of that element filled with a material. If an Eulerian element is completely filled with material, its EVF is 1 . If there is no material in the element, its EVF is 0. The interface between structure and subsoil can be represented using the boundary of the Lagrangian domain. The interested reader is referred to Benson $(1992,1995,2000)$ for a detailed derivation.

Contact between the Eulerian and Lagrangian domain is utilized using the general contact algorithm inside Abaqus, which is based on a penalty contact method described by Benson and Okazawa (2004). The Lagrangian elements can move through the Eulerian mesh without resistance until they encounter an Eulerian element filled with material. Seed points are created on the Lagrangian element edges and faces while anchor points are created on the Eulerian material surface. The penalty method approximates hard pressure-over closure behaviour, which allows small penetration of the Eulerian material into the Lagrangian domain. The formula for the penalty contact reads:

$$
\mathrm{F}_{\mathrm{p}}=\mathrm{k}_{\mathrm{p}} \mathrm{d}_{\mathrm{p}}
$$

where $F_{p}$ - contact force that is enforced between the seeds and anchor points, $\mathrm{k}_{\mathrm{p}}$ - penalty stiffness which depends on the Lagrangian material on one side and on the Eulerian material on the other side and $d_{p}-$ penetration distance.

\section{Constitutive model}

The hypoplastic constitutive model from von Wolffersdorff (1996), with the small-strain extension by Niemunis and Herle (1997) is used to simulate the behaviour of the soil. This constitutive model is able to adequately represent the nonlinear and anelastic behaviour of granular materials. It is framed in rate dependent formulation. Soil properties including contractibility, dilatancy and the change of stiffness result from the analysis and are stress and state dependent. The Abaqus implementation was done using a user subroutine provided by Gudehus et al. (2008).

\section{Numerical model}

The applied three-dimensional numerical simulation model is shown in Figure 6. In order to reduce computational time, symmetry conditions were used and only a 
$90^{\circ}$ slice was modelled. The numerical simulation model was validated in a first step against the previously described centrifuge experiments. Prototype dimensions are used. To avoid reflections at the boundaries, infinite elements have been attached to the back surface of the numerical model. The pile was installed force controlled by impact-driving and displacement controlled by vibratory-driving. The force is acting on the pile during impact-driven installation with a maximum $\mathrm{f}_{\max }$ of $50 \mathrm{kN}$ acting on the $90^{\circ}$ slice of the pile.

In Table 1 , the constitutive parameters used for the validation of the numerical model are shown. Cyclic parameters for the small strain, intergranular strain respectively were used. During the validation it could be observed that the small range between minimum void ratio $\mathrm{e}_{\mathrm{d} 0}$ and maximum void ratio $\mathrm{e}_{\mathrm{i} 0}$ proved problematic for a successful simulation. The simulation was terminated prematurely. Experience by the authors has shown that the in here used hypoplastic constitutive model is running into trouble when the relative density of the soil exceeds $85 \%$. Then large number of iterations is necessary and the simulation is likely to fail. Especially for the impactdriven pile a highly densified zone inside the pile is start to build. This zone leads to a high residual stress in the soil and the pile is not able to further penetrate into the soil (Fig. 9). Furthermore it is possible that grain crushing occurred in the centrifuge test in areas of high stress. The formulation of the hypoplasticity used in this paper is not able to simulate the effect of grain crushing.

Table 1. Hypoplastic parameters of the UWA centrifuge sand according to Henke (2013) with cyclic parameters of the intergranular strain

\begin{tabular}{lll}
\hline$\varphi_{\mathrm{c}}$ & {$\left[{ }^{\circ}\right]$} & 30 \\
$\mathrm{~h}_{\mathrm{s}}$ & {$\left[\mathrm{MN} / \mathrm{m}^{2}\right]$} & 1354 \\
$\mathrm{n}$ & {$[-]$} & 0.34 \\
$\mathrm{e}_{\mathrm{d} 0}$ & {$[-]$} & 0.49 \\
$\mathrm{e}_{\mathrm{co}}$ & {$[-]$} & 0.79 \\
$\mathrm{e}_{\mathrm{i} 0}$ & {$[-]$} & 0.86 \\
$\alpha$ & {$[-]$} & 0.18 \\
$\beta$ & {$[-]$} & 1.27 \\
$\mathrm{R}$ & {$[-]$} & 0.0001 \\
$\mathrm{~m}_{\mathrm{R}}$ & {$[-]$} & 2.2 \\
$\mathrm{~m}_{\mathrm{T}}$ & {$[-]$} & 1.1 \\
$\beta_{\mathrm{r}}$ & {$[-]$} & 0.936 \\
$\chi$ & {$[-]$} & 1.485 \\
\hline
\end{tabular}

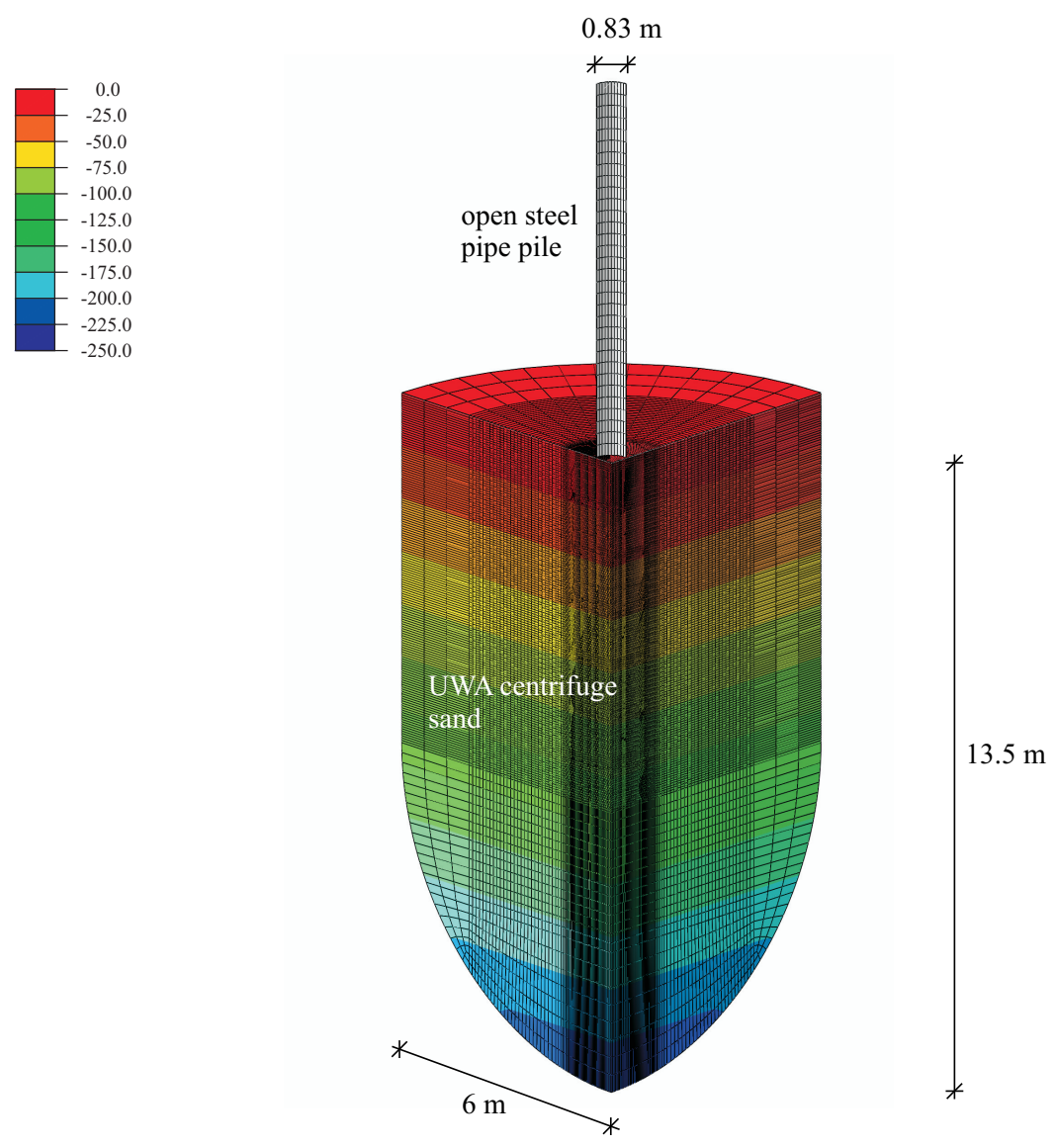

Fig. 6. Numerical model showing the initial vertical stress and the discretization around the pile 


\section{Results}

Different results can be obtained from the numerical simulations, e.g. the densification and loosening zones around the pile shaft and the zone influenced by the installation process. The contour plots in Figure 7 visualize the radial stress around the pile. The difference between the two different installation methods, impact-driving and vibratory-driving, cannot be investigated. This is related to the premature termination of the analysis. The impact-driven pile could be installed up to a length of $2.0 \mathrm{~m}$, the vibratory-driven pile up to a length of $3.6 \mathrm{~m}$. It is evident that the result of the impact-driven pile may differ with increasing embedment length, i.e. a direct comparison of the results with regard to the installation method is not possible. During the impact-driven installation of the pile, the soil inside the pile is not pushed downwards until the termination of the simulation.

Figure 8 shows the void ratio distribution in the soil during installation. The soil around the impact-driven pile shows loosening directly at the pile shaft. At the inside the entire soil is densified. Furthermore at the top of the soil layer the soil is slightly influenced and densified up to a distance of $1.5 \mathrm{D}$ from the pile shaft while at the pile toe a strong influence is visible up to a distance of $1 \mathrm{D}$. The soil around the vibratory-driven pile however shows a different behaviour. Directly at the pile shaft the soil is also loosened. A big difference is the area of influence. The soil is strongly influenced and densified up to a distance of 5.5 $\mathrm{D}$ to the pile shaft. This distance is almost constant over the whole embedment length. Underneath the pile toe, the soil is densified up to $12 \mathrm{D}$.
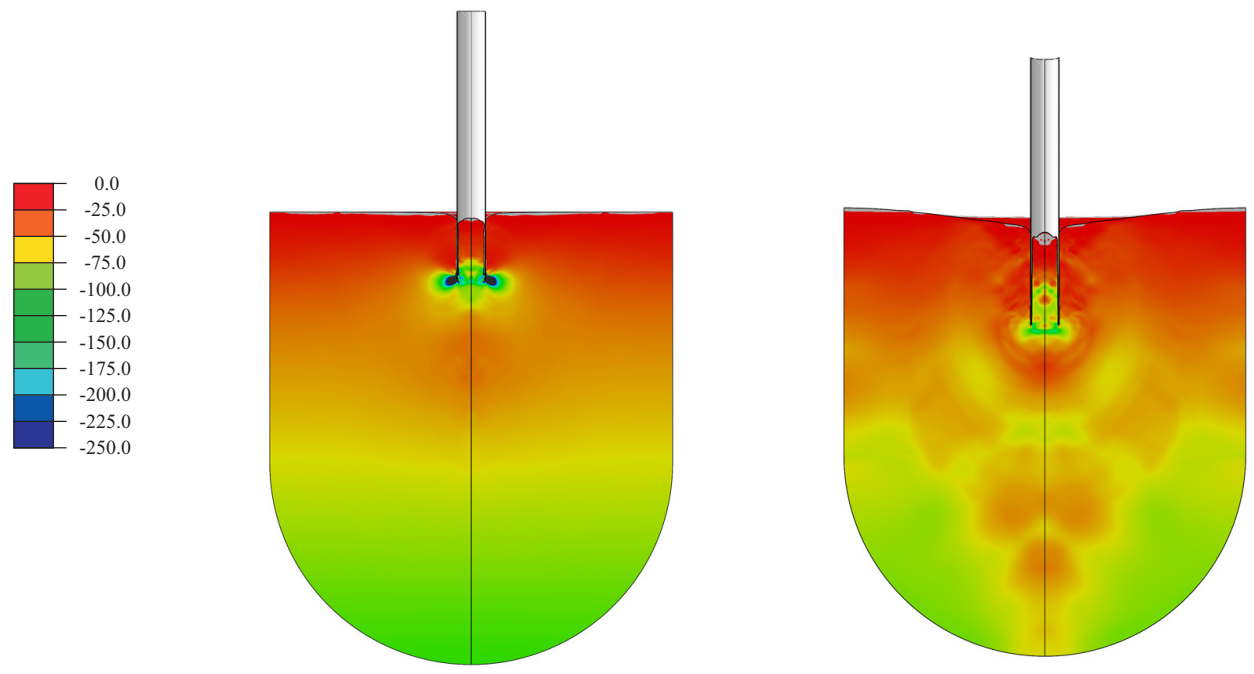

Fig. 7. Radial stress in the soil. Left: Impact-driven embedded $2.0 \mathrm{~m}$; Right: Vibratory-driven embedded $3.6 \mathrm{~m}$
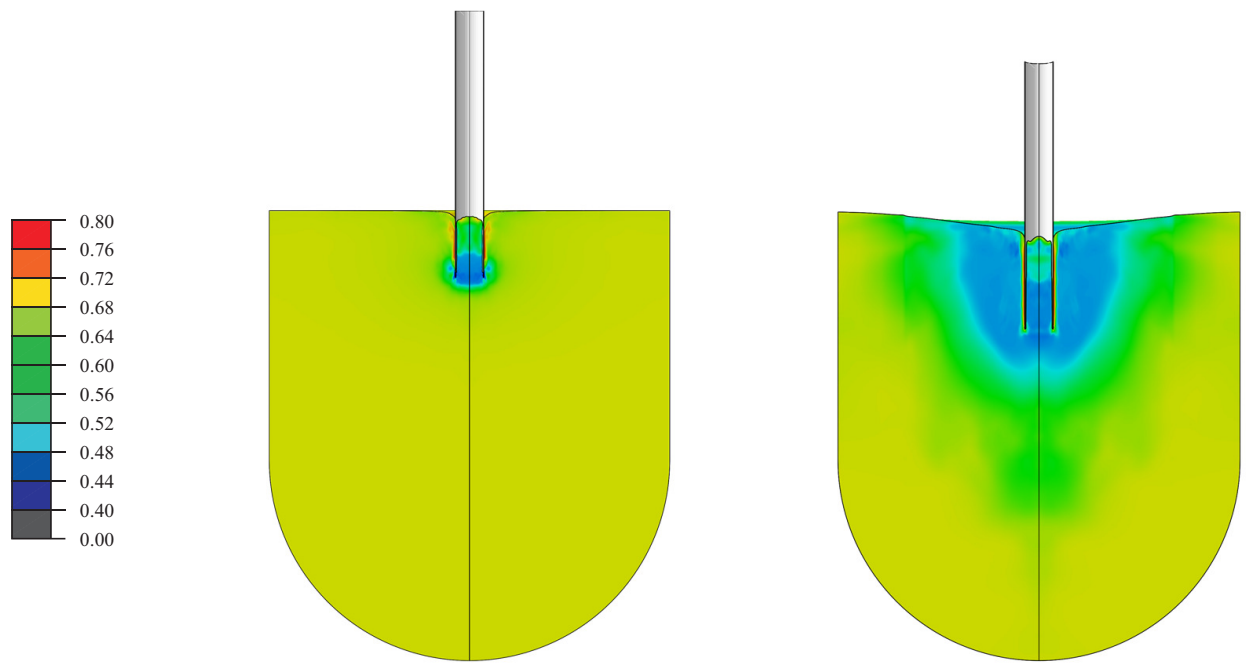

Fig. 8. Void ratio in the soil. Left: Impact-driven embedded $2.0 \mathrm{~m}$; Right: Vibratory-driven embedded $3.6 \mathrm{~m}$ 

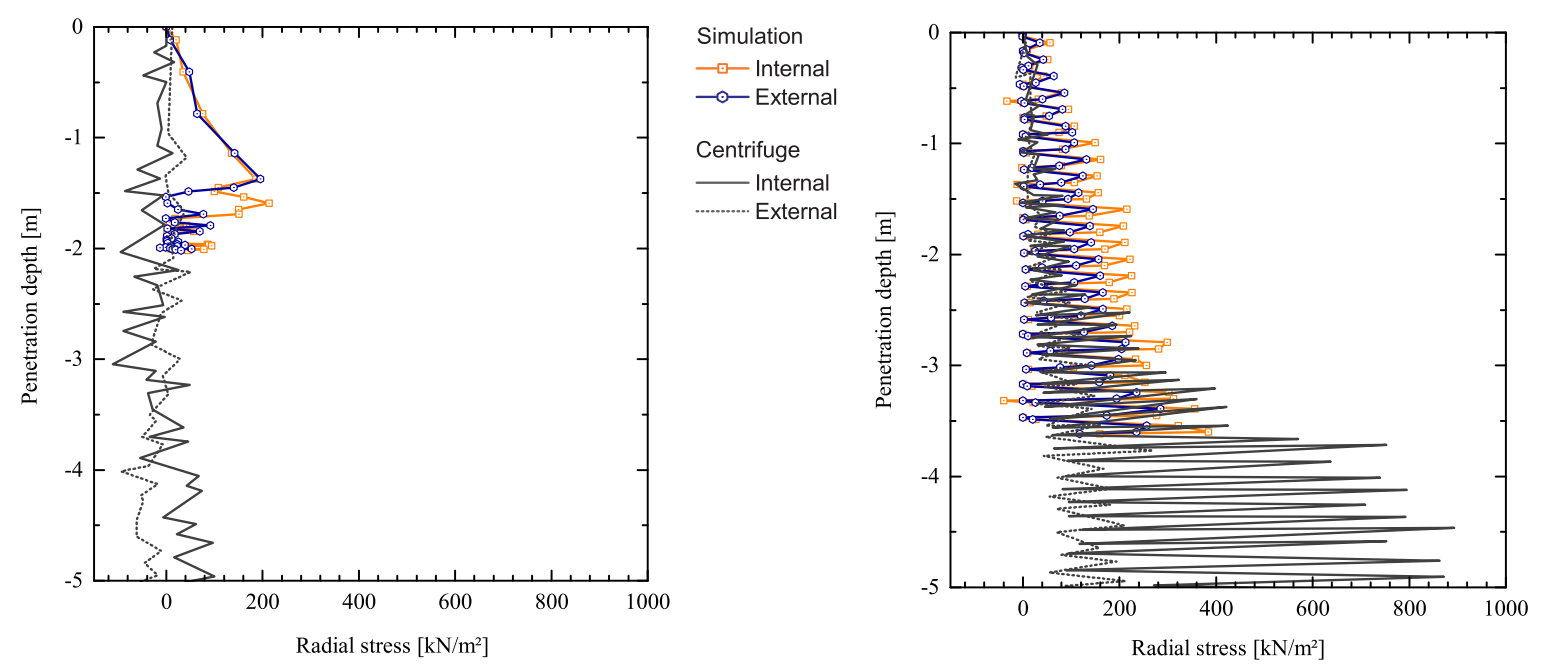

Fig. 9. Comparison of the results of the centrifuge study carried out by Henke and Bienen (2014) with the results of the numerical simulation: the radial stress at the in- and outside of the shaft during installation. Left: impact-driven installation; Right: vibratory-driven installation

As stated at the beginning of this paper, plugging occurs if the radial stress on the inside of the pile is higher than the radial stress on the outside. In Figure 9 the radial stress around the pile toe during installation is illustrated. As a result of the numerical simulation, the radial stress around the pile toe installed vibratory-driven shows no significant difference between the in- and outside. On the inside the stress is slightly higher than at the outside. That means that during vibratory-driving arching effects could arise. This is coherent with findings by Lammertz (2008) who states that also in vibratory-driven open steel pipe piles arching inside the pile can occur.

By comparing the results of the centrifuge study with the results of the numerical simulation (Fig. 9), it is evident that the radial stresses of the impact-driven pile do not match during the first meter of driving. Afterwards, the radial stress is converging with the measured stress. The calculated radial stress around the vibratorydriven pile however looks more feasible. At the beginning of the penetration the calculated stresses overestimate the stresses measured in the centrifuge study. From a penetration depth of $2.5 \mathrm{~m}$ the calculated stresses start to converge with the measured stresses. The stress at the inside of the pile is almost equal. The stress outside the pile is still overestimated by the numerical simulation. However, a qualitative comparison of the trend of the curves shows similar behaviour. The stress inside the pile is always higher than outside.

\section{Conclusions}

In this paper an approach to simulate the effect of plugging inside open steel pipe piles with regard to different installation methods has been presented. After clarifying the theoretical approaches to characterise a soil plug and the theoretical soil mechanical mechanisms during installation, a numerical study was presented. The numerical simulation clearly shows the possibility to simulate plugging effects and thus, be able to efficiently determine the bearing behaviour of the pile. Furthermore this simulation leads to a better understanding of the soil mechanical mechanisms during pile installation and helps to understand how the soil is influenced by the pile installation. Even research has already been conducted about this topic (e.g. Hartung 1994), it is not fully investigated yet. Especially for vibratory-driven piles, there are only a few approaches available to determine the bearing behaviour (e.g. Lammertz 2008).

Nevertheless, it should be noted that these numerical simulations are not straightforward. To validate the numerical model itself it is important to choose an adequate model test. On one hand this model test should deliver a sufficient amount and quality of results. But on the other hand it has to be noted, that these model tests are always scaled tests. The centrifuge study used in here for the validation of the numerical model provides the measurement of stresses during the pile installation. It could be seen as well, that the constitutive model plays an important role for the validation. Especially the simulation of the force controlled, impact-driven pile installation clearly indicates the limits of the in here used constitutive model. Effects like grain crushing, which can occur during pile installation, could not be modelled and thus leading to high residual stresses at the pile toe.

Furthermore it can be concluded that large numerical models are necessary to simulate the pile installation process. During the installation, large amounts of energy are distributed along the pile into the soil. The distance of the pile to the boundaries has to be that large that the influence of boundary conditions onto the latter result is minimized. This large numerical model leads to a huge amount of computational power needed to simulate the installation process. The in here presented simulations were conducted on a computer cluster utilizing 60 cores 
in parallel. Even though in the back-analysis of model tests the size of the numerical model is fixed, the influence has to be taken into account when transferring the model to real scale.

In conclusion, the numerical simulation of plugging effects with regard to the installation method vibratorydriving is possible. The numerical simulation of the force controlled, impact-driven installation process still needs to be investigated. However, the results of these simulations will help to gain a better understanding of the complex soil-structure interaction in general and the bearing behaviour of open steel pipe piles in detail.

\section{Acknowledgements}

The authors thank the Centre for Offshore Foundation Systems for providing the results of the centrifuge study. The numerical simulations were performed on the computational resource ForHLR Phase I funded by the Ministry of Science, Research and the Arts Baden-Württemberg and DFG ("Deutsche Forschungsgemeinschaft").

\section{References}

Benson, D. J. 1995. A multi-material Eulerian formulation for the efficient solution of impact and penetration problems, Computational Mechanics 15(April 1994): 558-571. http://dx.doi.org/10.1007/BF00350268

Benson, D. J. 2000. An implicit multi-material Eulerian formulation, International Journal for Numerical Methods in Engineering 48: 475-499. http://dx.doi.org/10.1002/(SICI)1097-0207(20000610) 48:4<475::AID-NME881>3.0.CO;2-U

Benson, D. J. 1992. Computational methods in Lagrangian and Eulerian hydrocodes, Computer Methods in Applied Mechanics and Engineering 99: 235-394. http://dx.doi.org/10.1016/0045-7825(92)90042-I

Benson, D. J.; Okazawa, S. 2004. Contact in a multi-material Eulerian finite element formulation, Computer Methods in Applied Mechanics and Engineering 193: 42774298. http://dx.doi.org/10.1016/0045-7825(92)90042-I

Brucy, F.; Meunier, J.; Nauroy, J.-F. 1991. Behaviour of a pile plug in sandy soils during and after driving, in Offshore Technology Conference, 1991, Houston.

Bruno, D. 1999. Dynamic and static load testing of driven piles in sand: $\mathrm{PhD}$ thesis. The University of Western Australia.

Dassault Systemes. 2014. ABAQUS 6.14 Manual.

De Nicola, A. 1994. Performance of pipe piles in sand: $\mathrm{PhD}$ Thesis. The University of Western Australia.

De Nicola, A.; Randolph, M. F. 1994. Development of a miniature pile driving actuator, in International Conference Centrifuge '94, 31 August - 02 September 1994, Singapore. CRC Press/Balkema.

De Nicola, A.; Randolph, M. F. 1997. The plugging behaviour of driven and jacked piles in sand, Géotechnique 47(4): 841-856. http://dx.doi.org/10.1680/geot.1997.47.4.841

Gudehus, G.; Amorosi, A.; Gens, A.; Herle, I.; Kolymbas, D.; Mašín, D.; Muir Wood, D.; Nova, R.; Niemunis, A.; Pastor, M.; Tamagnini C. G. V. 2008. The soilmodels.info project, International Journal for Numerical and Analytical Methods in Geomechanics 32(12): 15711572. http://dx.doi.org/10.1002/nag.675
Garnier, J., et al. 2007. Catalogue of scaling laws and similitude questions in geotechnical centrifuge modelling, International Journal of Physical Modelling in Geotechnics 7(3): 01-23.

http://dx.doi.org/10.1680/ijpmg.2007.070301

Hartung, M. 1994. Einflüsse der Herstellung auf die Pfahltragfähigkeit in Sand: $\mathrm{PhD}$ Thesis. Technische Universität Braunschweig (in German).

Henke, S. 2013. Untersuchungen zur Pfropfenbildung infolge der Installation offener Profile in granularen Böden: $\mathrm{PhD}$ Thesis. Technische Universität Hamburg-Harburg (in German).

Henke, S.; Bienen, B. 2013. Centrifuge tests investigating the influence of pile cross-section on pile driving resistance of open-ended piles, International Journal of Physical Modelling in Geotechnics 13(2): 50-62.

http://dx.doi.org/10.1680/ijpmg.12.00012

Henke, S.; Bienen, B. 2014. Investigation of the influence of the installation method on the soil plugging behaviour of a tabular pile, in C. Gaudin, D. White (Eds.). Proceedings of the 8th International Conference on Physical Modelling in Geotechnics, 14-17 January 2014, Perth, Australia. CRC Press.

Kezdi, A. 1969. Bodenmechanik, Bd. 1-3. Budapest, Berlin: VEB Verlag für Bauwesen.

Lammertz, P. 2008. Ermittlung der Tragfähigkeit vibrierter Stahlrohrpfähle in nichtbindigem Boden: PhD Thesis. Universität Duisburg-Essen (in German).

Lüking, J. 2010. Tragverhalten von offenen Verdrängungspfählen unter Berücksichtigung der Pfropfenbildung in nichtbindigen Böden: $\mathrm{PhD}$ Thesis. Universität Kassel (in German).

Lüking, J.; Kempfert, H. G. 2012. Untersuchung der Pfropfenbildung an offenen Verdrängungspfählen, Bautechnik 89: 264-274. http://dx.doi.org/10.1002/bate.201201545

Moormann, C.; Aschrafi, J. 2014. Numerical investigation of passive loads on piles in soft soils, Geotechnical Engineering Journal of the SEAGS \& AGSSEA 45(2): 1-11.

Moormann, C.; Labenski, J.; Aschrafi, J. 2015. Simulation of soil plug effects in open steel pipe piles considering the complex soil-structure-interaction during installation, in Proceedings of the $40^{\text {th }}$ Conference on Deep Foundations, 12-14 October 2015, Oakland, USA.

Niemunis, A.; Herle, I. 1997. Hypoplastic model for cohesionless soils with elastic strain range, Mechanics of Cohesive-Frictional Materials 2: 279-299. http://dx.doi.org/10.1002/(SICI)1099-1484(199710)2: 4<279::AID-CFM29>3.0.CO;2-8

Qiu, G.; Henke, S.; Grabe, J. 2009. Applications of Coupled Eulerian-Lagrangian Method to Geotechnical Problems with Large Deformations, in SIMULIA Customer Conference, 18-21 May 2009, London, England.

Randolph, M. F. 2003. Science and empiricism in pile foundation design, Géotechnique 53(10): 847-875.

von Wolffersdorff, P. 1996. A hypoplastic relation for granular materials with a predefined limit state surface, Mechanics of Cohesive-Frictional Materials 1: 251-271. 